Foreword

\title{
Precision Surgery in Obstetrics and Gynecology: Abdominal Hysterectomy
}

\author{
Yuji Hiramatsu, MD, $\mathrm{PhD}^{1}$ \\ ${ }^{1}$ Department of Obstetrics and Gynecology, Okayama City General \\ Medical Center, Kita-Ku, Okayama, Japan
}

Surg J 2019;5(suppl S1):S1.

I'm delighted to be publishing the inaugural issue of Precision Surgery in Obstetrics and Gynecology (PSOG), a supplement to The Surgery Journal, with the editorial cooperation of Professor Ikuo Konishi, Professor Noriaki Sakuragi, and Professor Satoru Takeda. PSOG is created with the following policies: (1) Explaining the basics and applications of obstetric and gynecologic surgery using beautiful, easy-to-understand illustrations in a simple manner; (2) Explaining the tips of surgery and the methods to avoid complications of surgery.

We have previously published a Japanese book series (24 volumes), entitled Obstetric and Gynecologic Surgery Now (OGS Now) ${ }^{1}$ with the Japanese medical publisher, Medical View, Inc. The beautiful illustrations and concepts of OGS Now caught the eye of The Surgery Journal published by Thieme Medical and Scientific Publishers, and thanks to Medical View, we were able to publish this English supplement by using illustrations from OGS Now. In PSOG, the concept of OGS Now publication is inherited, and further modifications are made to the representative surgical arti- cles published in OGS Now. We will take up typical obstetrics and gynecology surgery in every time and explain it in an easy-to-understand manner.

Our inaugural issue focuses on "Abdominal Hysterectomy," with four manuscripts, demonstrating individualized operative techniques. We sincerely thank Medical View for supporting this project and for providing illustrations used in OGSNow. The articles published in this supplement will be read by several obstetricians and gynecologists around the world, and we hope to contribute to the provision of safe surgery.

Conflict of Interest

None declared.

\section{Reference}

1 Hiramatsu Y, Konishi I, Sakuragi N, Takeda S. Obstetric and Gynecologic Surgery Now (OGS Now). Vol. 1-24. Tokyo: Medical View; 2010-2015
Address for correspondence Yuji Hiramatsu, MD, PhD, Okayama City General Medical Center, 3-20-1 Kitanagase Omotematchi, Kita-Ku, Okayama 700-8557, Japan (e-mail: kiki1063@ cc.okayama-u.ac.jp).
DOI https://doi.org/ 10.1055/s-0039-1691829. ISSN 2378-5128.
Copyright (C) 2019 by Thieme Medical Publishers, Inc., 333 Seventh Avenue, New York, NY 10001, USA. Tel: +1(212) 584-4662.

\section{License terms}

(c) (1) $\ominus$ (5) 